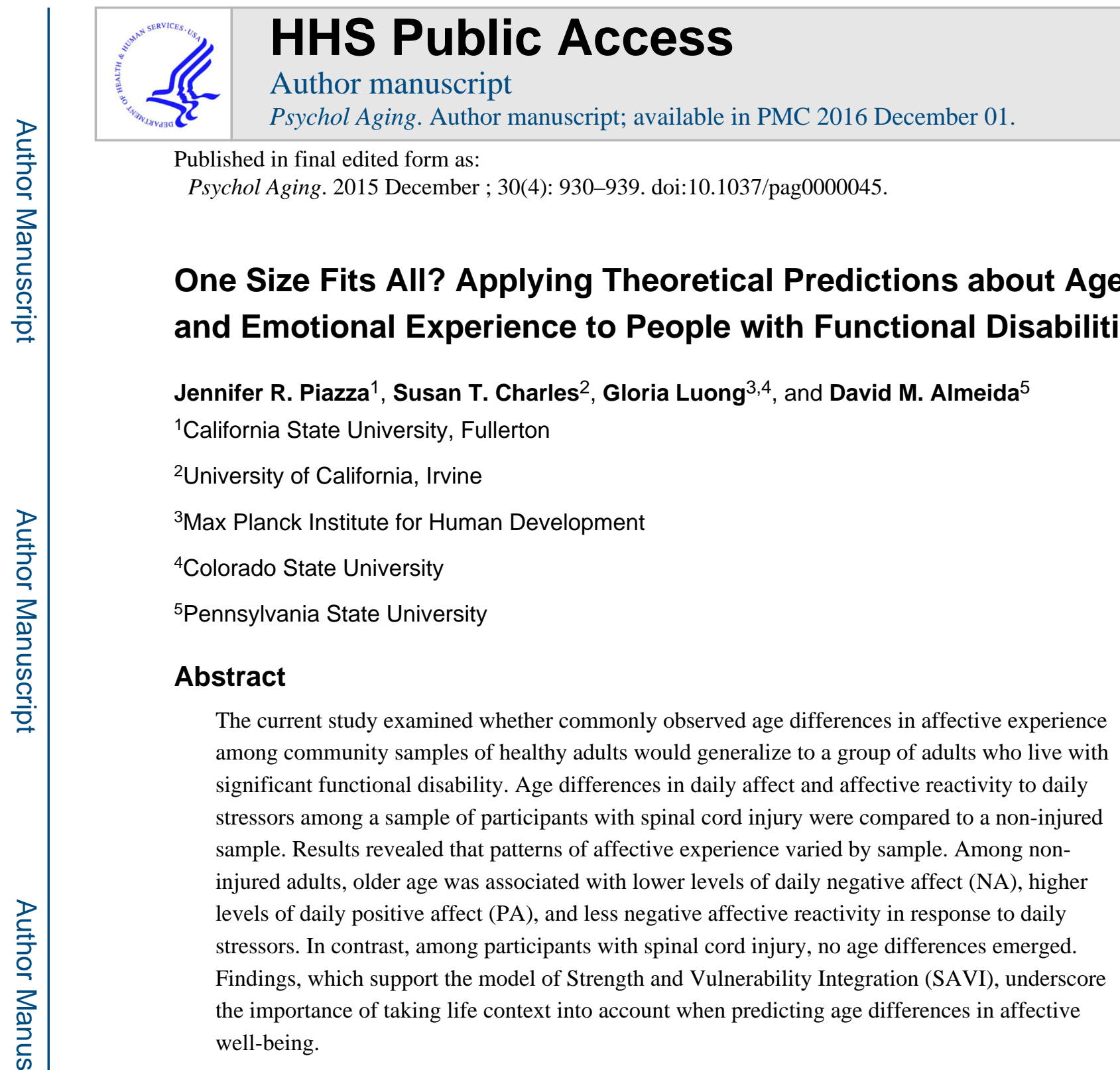

\title{
Keywords
}

Aging; emotion; affect; disability; spinal cord injury

\begin{abstract}
Studies frequently document intact, and even improved, affective well-being across adulthood (for reviews, see Charles \& Carstensen, 2010; Charles \& Piazza, 2009). The majority of these studies, however, focus predominantly on healthy adults, and it is unclear how physical health problems may alter age-related differences in affective experience. People with physical health problems often face unpredictable, stressful demands due to their condition and are more likely to report affective distress and affective disorders than their healthy counterparts (e.g., Piazza, Charles, \& Almeida, 2007; Wolff, Starfield, \&
\end{abstract}

Address correspondence to Jennifer R. Piazza, 243 KHS, Department of Health Science, California State University, Fullerton, Fullerton, CA 92831; jpiazza@ fullerton.edu.

Jennifer R. Piazza, Department of Health Science, California State University, Fullerton; Susan T. Charles, Department of Psychology and Social Behavior, University of California, Irvine; Gloria Luong, Max Planck Research Group "Affect Across the Lifespan,"Max Planck Institute for Human Development and Department of Human Development and Family Studies, Colorado State University; David M. Almeida, Department of Human Development and Family Studies, Pennsylvania State University. 
Anderson, 2002). Rarely, however, have researchers examined how age-related patterns of affective experience may differ for individuals with health problems, such as functional disabilities. According to the model of Strength and Vulnerability Integration (SAVI), the strength of aging lies in older adults' increased use of strategies that allow them to avoid highly distressing situations (Charles, 2010). When avoidance of highly stressful situations is difficult or impossible, SAVI predicts that age differences in emotion regulation abilities will be attenuated or disappear completely. The current study tests SAVI using two national samples: a sample comprised of adults with spinal cord injury and a sample comprised of adults reporting no functional limitations.

\section{Age and emotional experience}

A number of studies have documented higher levels of positive affect and lower levels of negative affect among older adults compared to younger adults (e.g., Carstensen et al., 2011; Riediger, Schmiedek, Wagner, \& Lindenberger, 2009; Stone, Schwartz, Broderick, \& Deaton, 2010; for review, see Charles \& Piazza, 2009). Among the oldest adults, however, age-related patterns sometimes reveal no differences or even upturns in negative affect and downturns in positive affect (e.g., Mroczek, 2001). Terminal decline likely accounts for some of these findings (e.g., Gerstorf, Ram, Mayraz, Hidajat, Lindenberger, Wagner, \& Schupp, 2010), but other factors may also be involved.

The model of Strength and Vulnerability Integration (SAVI) was formulated to explain how life circumstances influence age differences in emotion regulation strategies and overall levels of affective well-being (Charles, 2010; Charles \& Luong, 2013; Charles \& Piazza, 2009). According to SAVI, older adults are motivated to maintain affective well-being because of their perception of time left in life (as posited and described by socioemotional selectivity theory; Carstensen, 2006), and are better equipped to do so because of the knowledge and experience acquired from years already lived. Older adults are therefore more likely to avoid exposure to negative experiences (e.g., Blanchard-Fields, 2007) or, when avoidance is impossible, to effectively modify their affective responses to caustic experiences.

\section{Emotions in context}

By integrating environmental context and other life circumstances with age-related motivations and abilities, researchers can better predict when age-related improvements in well-being will be most pronounced, and when they will not be present or even reverse in direction. Specifically, some life experiences make it particularly difficult to avoid stressors and/or to modify one's appraisals of stressful events. For example, life experiences such as loss of social belonging, exposure to chronic, uncontrollable stressors, and neurological dysregulation are all associated with high levels of distress. In addition, these experiences (e.g., neurological dysregulation in the form of cognitive impairment) increase in prevalence with age. Thus, although the motivation to maintain affective well-being exists, certain circumstances impinge upon older adults' ability to do so (Charles, 2010). SAVI posits, then, that the reason why some studies fail to show age-related improvements in affective 
well-being is that certain life contexts may prevent older adults from avoiding highly arousing, unpleasant events.

Of course, even though these situations increase in frequency with age (see reviews by Hawkley \& Cacioppo, 2007; Park, 2002), they are not confined to old age. Younger adults can and do experience adverse circumstances such as loss of social belonging (e.g., Leary, 1990; Stroebe, Schut, \& Stroebe, 2007) and neurological dysregulation (Salthouse, 2004). What happens, then, to age differences in affective experience among people living in similar difficult circumstances? One study found that older adults with multiple chronic health conditions were just as emotionally reactive to daily stressors as were younger adults who reported the same number of health conditions (Piazza et al., 2007). Although this study lends some support to SAVI, one issue with studying age differences in the context of chronic health conditions is that chronic health conditions are more normative in later adulthood, and thus more of an "on-time" event.

On-time or off-time events refer to the normative timing of positive or negative events at particular stages in life (Neugarten, 1979). Researchers posit that coping with a negative life event is particularly difficult when it occurs earlier than what is commonly predicted. Indeed, studies suggest that younger individuals have greater problems adjusting to spousal bereavement (e.g., Stroebe et al., 2007) and chronic illness (Aldwin, Sutton, Chiara, \& Spiro, 1996) than do older adults. When an event happens at a more normative age, people may not only have anticipated the event, but may also have same-aged peers living with the same difficult situation. Thus, the influence of the on-time versus off- time phenomena represents confounds in previous investigations of age differences in emotional experience among people faced with problems more common in later life.

\section{The context of spinal cord injury (SCl)}

One life circumstance that is not age- normative-and therefore not subject to the issue of on-time/off-time events-is the occurrence of a spinal cord injury. At no age is living with SCI normative: older adults will not have foreseen, planned or expected to be living with SCI any more than younger adults. SCI is a severe, disabling condition that affects approximately 273,000 people in the United States, with 12,000 new cases per year (National Spinal Cord Injury Statistical Center, 2013). Living with SCI presents a number of physical and emotional challenges, from adjusting one's activities due to health and functional constraints to facing potential societal stigma. Rates of emotional disorders among people with SCI are twice that of non-injured adults (Migliorini, Tonge, \& Taleporos, 2008) and rates of suicide significantly higher (for review, see Giannini et al., 2010). In contrast, levels of subjective well-being (Fuhrer, 1996) and life satisfaction are significantly lower (Kemp \& Krause, 1999) in this population. Few studies, however, have examined age differences in affective experience among people with SCI.

\section{Affective reactivity}

We were interested in applying SAVI to examine age-related patterns in daily affective experiences, and particularly age differences in affective reactivity in response to daily stressors, among people with SCI compared to people without SCI. Daily stressors, such as 
an impending work deadline, an argument with a significant other, or a missed appointment, are the hassles that disrupt daily life (Almeida, 2005). Previous findings examining age differences in affective reactivity to daily stressors are mixed, with some research finding age-related improvements in affective reactivity (e.g., Almeida \& Horn, 2004; Birditt, Fingerman, \& Almeida, 2005), some reporting null effects (e.g., Diehl \& Hay, 2010; Neupert, Almeida, \& Charles, 2007), and some finding greater reactivity with age (e.g., Aldwin, Jeong, Igarashi, Choun, \& Spiro, 2014; Sliwinski, Almeida, Smyth, \& Stawski, 2009). The discrepancies across studies in patterns of age differences in affective reactivity to stressors may be partially explained by the ability of people to disengage from these situations (e.g., Birditt \& Fingerman, 2005; Luong \& Charles, 2014). In one study, for example, older adults reported less affective distress than younger adults on days when they actively avoided an argument (Charles, Piazza, Luong, \& Almeida, 2009). On days when an argument occurred, however, no age-related differences in affective experience emerged. Moreover, younger adults reported equally strong reactivity for both situations, whereas older adults reported less reactivity on days they actively avoided an argument compared to days when they reported having an argument.

Avoiding stressful situations may reflect older adults' motivation to structure their daily life in a way that allows for the maintenance of affective well-being (e.g., Blanchard-Fields, 2007; Luong, Charles, \& Fingerman, 2011). Indeed, when older adults are unable to use disengagement strategies effectively, such as when they continue to be mentally preoccupied by recent daily hassles, they exhibit increased levels of negative affect relative to younger individuals (Wrzus, Luong, Wagner, \& Riediger, 2015). Research indicates that people with SCI face not only the same stressors as their non-injured peers but also a number of severe disability-related stressors (Degraff \& Schaffer, 2008; Schopp et al., 2007). Moreover, the nature of stressors faced by people with SCI (e.g., bowel/bladder problems, inaccessibility in public places, medical complications) makes avoidance and disengagement from aversive situations very difficult—if not impossible (Degraff \& Schaffer, 2008). For example, people with SCI face a number of environmental barriers in their day-to-day life (Lysack, Komanecky, Kabel, Cross, \& Neufeld, 2007), including perceived barriers to employment, such as transportation and workplace accessibility (Schopp et al., 2007). They also report difficulty fulfilling social role obligations and completing activities of daily life without assistance (Noreau \& Fougeyrollas, 2000). Thus, for people with SCI, the motivation to avoid or actively disengage from stressors may exist, but the barriers they encounter in their daily life make it more difficult to do so when compared to their same-aged, non-injured peers.

\section{The current study}

In the current study, we examined age differences in daily affect and affective reactivity to daily stressors among people living with a spinal cord injury, and compared this pattern to a sample of participants from the National Study of Daily Experiences (NSDE II) who did not have a spinal cord injury and who reported having no functional limitations. Based on SAVI, we hypothesized that age-related benefits in daily affect and affective reactivity to daily stressors would be present in the non-injured sample (NSDE II), but would be attenuated in the sample of participants with spinal cord injury. To focus on age differences 
in relatively normative, daily emotion regulation processes as opposed to age differences in response to adjustment to injury (Krause \& Crewe, 1991), we recruited participants with SCI who had been injured for at least five years. Moreover, although people with SCI have a life expectancy of about 70-92\% of the population life expectancy (Yeo et al., 1998), their condition does not suggest a terminal diagnosis (Garshick et al., 2005). Thus, concerns of terminal decline are reduced for this condition compared to others with more life-limiting prognoses.

\section{Method}

\section{Participants and Procedure}

The National Study of Daily Experiences (NSDE II) sample-The NSDE II, which is the daily diary telephone interview portion of the second wave of the Midlife Development in the United States Survey (MIDUS II), was carried out at the same time as the data collection for the SCI sample (described below). NSDE II participants included a national sample of 1,079 MIDUS II participants who were recruited through random digit phone dialing and had no other family members in the study. Across eight consecutive evenings, NSDE II participants answered questions pertaining to the previous 24 hours, including their physical health and affective well-being, and any stressors they may have encountered. Because the goal of the current study was to examine differences between people with and without functional limitations, analyses were limited to those who reported no problems with activities of daily living (described in the measures section below; $n=$ 704). Interviews lasted approximately 20 minutes each and the first interview was staggered across day of the week. Participants were compensated $\$ 25.00$.

The sample with SCl-The sample with SCI included 239 participants who were recruited through the Reeve-Irvine Research Center and other SCI-related organizations. Participants on the Reeve-Irvine email listserv were emailed a description of the study with laboratory contact information. Participants were also recruited through SCI email listervs and websites, advertisements placed in regional and national SCI magazines and newsletters, and flyers. To be eligible to participate, individuals were required to be at least 18 years of age, to be free from any psychological disorder, and to have had an SCI for more than 5 years.

On average, participants with SCI had been injured for 20.3 years $(S D=11.66)$ at the time of the initial interview. Level of injury varied across participants: $52 \%$ were classified as tetraplegic, having sustained an injury at vertebrate level C7 or higher; $47 \%$ were classified as paraplegic, having sustained an injury at vertebrate level $\mathrm{T} 1$ or lower; the remaining $1 \%$ were unsure of their injury level. The majority of participants were injured in motor vehicle accidents $(40.3 \%)$ or other types of accidents (35.4\%). Medical problems, such as transverse myelitis and spina bifida, comprised $6.6 \%$ of all injuries, and $11.6 \%$ of participants were injured in other ways, such as gunshot wounds. Because cause of injury was not assessed in the interview protocol until after the study had already begun, data are missing for $6 \%$ of participants. Between 2006 and 2007, participants with SCI completed a series of daily diary telephone interviews, modeled after the protocol used in NSDE II. Prior to the daily diary 
interviews, participants with SCI completed an initial telephone interview lasting approximately one hour, which assessed demographic characteristics and overall physical and affective well-being. Subsequently, they completed a series of daily interviews, during which participants with SCI were asked the same questions as in the NSDE II about their daily physical health, affective well-being and whether they had experienced any stressors during the previous 24 hours (see Measures). Due to fiscal constraints, we were unable to interview a sample with SCI that was equivalent in size to the NSDE II sample. To more closely match the samples for total number of days interviewed, we extended SCI interviews to 15 consecutive days prior to the study's inception. This provided sufficient power at the daily level to examine differences between the two samples. Upon completing the study, participants were compensated $\$ 150.00$. Because of the slightly different age ranges of the NSDE II (34-84 years) and SCI samples (21-87 years), analyses for the current study were limited to participants with SCI 34 years and older, bringing the SCI sample size to 181 .

Creating a comparison subsample: The NSDE II and SCI samples differed on important demographic variables, so a comparison NSDE II subsample was created. Because of the difference in interview days ( 15 days for participants with SCI and 8 days for NSDE II participants), two NSDE II participants were retained $(n=362)$ for every participant with SCI $(n=181)$. This ensured that each sample had approximately the same number of interview days for all analyses. Only NSDE II participants who reported no functional limitations (described below) were included in this comparison group. Participants were matched according to age, gender and education, and when possible, ethnicity. The reason we could not entirely match on ethnicity was due to the small number of minority participants in NSDE II.

Age of participants did not differ between the two samples, $t(541)=.56, p=.52$; NSDE II: 50.7 years, $S D=11.0$; $S C I$ : 50.3 years, $S D=11.5$ ), and age ranges were nearly identical (NSDE II: 50 years; SCI: 53 years). Both samples had a similar number of females (NSDE: $50.6 \%$; SCI: $54.1,\left(\chi^{2}(1, N=543)=.62, p=.43\right)$ and reported similar levels of education, $(t(540)=-.56, p=.58)$, with nearly half of the participants in both samples reporting having a Bachelor's degree or higher (NSDE: 50.3\%; SCI: 47.2\%). Participants did, however, significantly differ in terms of marital status, $\chi^{2}(4, N=541)=42.9, p<.001$, and ethnicity, $\chi^{2}(4, N=543)=19.6, p<.001$. For a comparison of demographic characteristics for the NSDE II and SCI samples, see Table 1.

\section{Measures}

Activities of Daily Living (ADL)—In MIDUS/NSDE II, problems with ADL's were assessed by asking participants to rate on a four-point scale, ranging from "not at all" to "a lot," how much their health limits their ability to do each of the following activities: bathing/ dressing oneself; climbing one flight of stairs; and walking one block. Of the 1,079 NSDE II participants, 375 reported having some difficulty in one of these domains and were subsequently excluded as possible comparison participants.

Time since injury-Participants in the SCI sample were asked how long they had been injured. Answers ranged from a minimum of 5 years to a maximum of 65 years, with 
participants injured, on average, for 20.3 years $(S D=11.66)$. Research indicates that time since injury is associated with greater life adjustment among people with SCI (Krause, 1998). Since age was correlated with time since injury in the current study $(r=.24, p=.01)$, which could potentially confound any results, time since injury was included as a covariate in all models testing our hypotheses. To ensure that all people were included in the analyses, NSDE II participants were assigned a 0 for this variable.

Chronic physical health conditions-SCI and NSDE II participants were asked if they had been treated for or experienced 23 chronic health conditions in the past year (e.g., asthma, bronchitis or emphysema, gall bladder trouble, diabetes or high blood sugar; Marmot, Ryff, Shipley, \& Marks, 1997), which were later subsumed into 17 chronic condition categories. Participants with SCI reported significantly more chronic health conditions than did NSDE II participants, $t(281.2)=-11.2, p<.001$; NSDE II: 1.38 conditions, $S D=1.46$; SCI: 3.20 conditions, $S D=1.97$ ). In both samples, increasing age was associated with more chronic health conditions (NSDE II: $r=.25, p<.001$; SCI: $r=.29, p$ $<.001)$. For a complete listing of sample differences in chronic conditions, please see Table 2.

Daily negative affect (NA) - In both the NSDE II and SCI samples, daily NA was assessed using combined items from the Positive and Negative Affect Schedule (Watson, Clark, and Tellegen, 1988) and the revised Non-Specific Psychological Distress Scale (Kessler et al., 2002). Respondents indicated on a 5-point scale, anchored at 0 (none of the time) and 4 (all of the time) how much of the time they experienced each of the following emotions or emotion descriptors on each interview day: so sad nothing could cheer you up, nervous, restless/fidgety, hopeless, that everything was an effort, worthless, lonely, afraid, angry, and frustrated. Mean scores for these 10 items were calculated for each participant (for the NSDE II sample, daily a ranged from .66 - .79; for the SCI sample, daily a ranged from $.73-.83)$.

Daily positive affect (PA)-To assess daily PA in the NSDE II and SCI samples, participants rated on a 5-point scale, anchored at 0 (none of the time) and 4 (all of the time), how much of the time they experienced each of the following 10 emotions or emotion descriptors on each interview day: cheerful, in good spirits, extremely happy, calm and peaceful, satisfied, full of life, close to others, like you belong, enthusiastic, and proud. Mean scores for these 10 emotions were calculated for each participant, resulting in an average PA score (for the NSDE II sample, daily a ranged from .91 - .94; for the SCI sample, daily a ranged from $.91-.95$ ).

Daily stressors and affective reactivity-For both samples, daily stressors were assessed using the semi- structured Daily Inventory of Stressful Experiences (DISE; Almeida, Wethington, \& Kessler, 2002). The inventory consists of a series of seven stem questions asking whether certain types of daily stressors, such as a problem in the home or an argument with someone, had occurred in the previous 24 hours. For each daily interview, individuals responding affirmatively to any of the seven stressors were classified as having 
had experienced a stressor (1) and those who reported not experiencing a stressor were classified as having had experienced no stressors (0).

Person-mean average number of stressors was calculated by averaging the number of stressors each participant reported across the interview period and was used as a covariate in analyses examining reactivity to daily stressors (Hoffman \& Stawski, 2009).

Affective reactivity to daily stressors was operationalized as the within-person slope between stressors and negative affect and refers to an individual's change in NA or PA from a non-stressor day to a stressor day.

\section{Analyses and Results}

The first set of analyses examined sample and age differences in average levels of daily NA and PA. The second set of analyses tested sample and age differences in negative and positive affective reactivity to daily stressors. For all analyses, we used two-level hierarchical multi-level modeling (MLM) to examine between- and within-person differences (Raudenbush \& Bryk, 2002). In MLM, Level 1 represents within-person variability and Level 2 represents between-person variability. In all models, the Level 1 outcome variable, affect ${ }_{i t}$, refers to within-person variation in affect (either NA or PA) for person $\mathrm{i}$ on day $\mathrm{t}$, and is a function of a person-specific intercept, within-person error andfor the stressor reactivity models—-stressor exposure, which was included as a random effect.

In all models, Level 2 between-person variables included the sample (SCI or NSDE II), participant's age, and other demographic variables that differed by sample or that could influence age differences in affective experience: education, race (effect coded with White as the reference group), marital status (effect coded with Married as the reference group), gender (effect coded with female as the reference group), interview day (1-8 for NSDE II; 1-15 for SCI), time since injury (NSDE participants were assigned "0" for this variables so that they were not omitted from analyses), and random intraindividual variation. In followup analyses examining within-group differences we also statistically adjusted for injury level in the SCI group. In the stressor reactivity models, we also adjusted for the average number of daily stressors participants reported across the interview period. In subsequent models, interaction terms were included to test the hypotheses. For the daily affect models, we included a sample $\times$ age interaction term as a test of our hypotheses. For the stressor reactivity models, we included the following interactions: sample $\times$ age; stressor $\times$ age; stressor $\times$ sample; and a three-way sample $\times$ age $\times$ stressor interaction. In these models, the three-way interaction tested our main hypothesis. Analyses were conducted using SAS PROC MIXED (SAS Institute, 2001) and estimated from unstructured covariance matrices by means of full maximum likelihood.

\section{Daily negative affect}

Results from analyses examining daily NA are presented in Table 3, Model 1 . This model revealed a significant age $\times$ sample interaction, which indicated that older age was related to lower daily NA in the NSDE II sample, but was unrelated to daily NA in the SCI sample 
(see Figure 1). To examine this interaction further, we conducted two separate MLM's with daily NA as the outcome variable; the first model examined only the NSDE II participants; the second model only examined only SCI participants. Whereas the NSDE II analyses showed a significant, negative effect of age on NA $(\beta=-.004, p<.001)$, the SCI analyses $\operatorname{did} \operatorname{not}(\beta=.002, p=.26)$, even when adjusting for level of injury $(\beta=-.001, p=.55)$.

Additional findings from the full model indicated that people who had never been married had higher levels of NA than those who were married $(\beta=.060, p<.05)$ and as the study progressed people reported less NA (Table 3, Model 1).

\section{Daily positive affect}

Results from analyses examining daily PA are presented in Table 4, Model 1. In this model, an age $\times$ sample interaction emerged, which revealed that although older age was related to higher levels of daily PA in the NSDE II sample, no age differences emerged in the SCI sample (see Figure 2). We once again conducted separate MLM's for each sample to examine this interaction further. Results revealed that increasing age was associated with higher levels of PA in the NSDE sample ( $\beta=.015, p<.001)$, but not the SCI sample $(\beta=$. $001, p=.90)$, even when adjusting for level of injury $(\beta=.007, p=.28)$. Additional findings in the full model revealed that higher levels of education were associated with lower levels of daily PA and that racial groups self-defined as "other" (i.e., not African-American, Asian, or Hispanic) reported higher levels of daily PA than did Whites.

\section{Affective reactivity to daily stressors}

Two sets of analyses were conducted to examine age and sample differences in affective reactivity in response to daily stressors. The first set of analyses examined NA reactivity; the second set of analyses examined PA reactivity.

Negative affective reactivity—Results examining NA reactivity are presented in Table 3 , Model 2. Results revealed a significant three-way age $\times$ sample $\times$ stressor interaction $(\beta$ $=.003, p=.04$; see Figure 3), which indicated that although age was related to lower stressor reactivity (i.e., change in NA from a stressor to a non-stressor day) in the NSDE II sample, it was unrelated to stressor reactivity in the SCI sample. To examine this interaction further, we conducted additional MLM's: the first examining only the NSDE II participants and the second examining only the participants with SCI. In analyses examining the NSDE II participants, an age $\times$ stressor interaction emerged, indicating that in the NSDE sample, increasing age was related to less reactivity to daily stressors $(\beta=-.003, p=.003)$. In the SCI sample, however, age was not significantly related to stressor reactivity $(\beta=.000, p=$. $72)$, even when adjusting for level of injury $(\beta=.001, p=.57)$. Findings from the full model also revealed that people who were never married reported higher levels of NA compared to married individuals $(\beta=.055, p=.02)$ as did people who reported a greater number of stressors across the week $(\beta=1.19, p<.001)$. In addition, time since injury was inversely associated with levels of NA $(\beta=-.004, p<.001)$ and people reported less NA as the interview days progressed.

Positive affect reactivity-No significant interactions emerged in an analysis examining age and sample differences in positive affect reactivity in response to stressors (i.e., change 
in positive affect from a stressor day to a non-stressor day; Table 4, Model 2). However, people who reported more stressors on average (regardless of age and sample) reported lower levels of PA than people reporting fewer stressors. People also reported lower levels of PA on days they encountered stressors.

\section{Discussion}

Researchers have offered various explanations for the paradox of well-being in later life, attributing it to reasons such as physiological changes in the brain (Cacioppo, Berntson, Bechara, Tranel, \& Hawkley, 2011) and developmental shifts in cognitive processing of information (Labouvie-Vief, 2003; see discussion by Isaacowitz \& Blanchard-Fields, 2012). The current study approaches this question from a contextual perspective, examining how the circumstance of living with a functional disability may alter patterns of age differences in daily affective experiences. Results indicate that among people with no significant functional disability, age was associated with higher levels of daily positive affect, lower levels of daily negative affect, and less negative affective reactivity in response to daily stressors. Among adults with functional disabilities as a result of spinal cord injury, however, no age differences emerged.

\section{Well-being among people with a disability}

The physical and functional challenges for people living with a disability are welldocumented (e.g., Alschuler et al., 2013). For people with SCI, prevalence rates of major depressive disorder are increased, and there are strong links between functional disability and depression (Dryden et al., 2005). Although successful treatment of depression and anxiety decrease disability levels (e.g., Lenze et al, 2001), the reverse association has also been well-established: functional disability is related to lower levels of well-being (e.g., Barry, Soulos, Murphy, Kasl, \& Gill, 2012; Hoffman, Bombardier, Graves, Kalpakjian, \& Krause, 2011). Longitudinal data suggest that although people adjust to an injury in the year after it occurs and return close to previous levels of well-being (hedonic treadmill), they never quite return to pre-injury levels of life satisfaction (see review by Lucas, 2007). Together, cross-sectional and longitudinal findings show that people who have sustained a SCI report lower levels of life satisfaction and higher rates of depression when compared with their non-injured counterparts, a pattern consistent with the results in the current study. What is unclear from previous literature, however, is whether age-related changes in affective experience documented in previous studies of relatively healthy people apply to people living with severe functional limitations.

\section{Strength and vulnerabilities of aging}

We predicted, based on SAVI, that age differences observed among people with no functional limitations would not replicate among people with SCI, particularly for affective reactivity - a dynamic measure that is believed to be indicative of emotion regulatory processes. SAVI predicts that strengths of aging lie within the ability of people to foresee negative events, and motivated by their time left in life (as posited by socioemotional selectivity; Carstensen, 2006), and their experiences gained throughout life, they proactively avoiding these situations (Charles \& Luong, 2014). When they cannot either avoid or 
extricate themselves from highly aversive circumstances, however, the vulnerabilities of physiological aging are hypothesized to make this experience more difficult to modulate. Although we did not study participants' physiological responses, we were able to examine affective reactivity in response to daily stressors. As predicted, the age-related decreases in negative affective reactivity we observed in the NSDE II sample were not replicated in the sample with SCI. In the sample with SCI, older adults were just as reactive to daily stressors as were younger adults.

\section{Health, age, and emotion}

A number of studies have examined the associations between age, health, and affect (e.g., Ong, Mroczek, \& Riffin, 2011). Many of these studies find that age is related to similar or lower levels of negative affect only after adjusting for physical health (e.g., Kunzmann, Little, \& Smith, 2000). The current study varies from these prior investigations because it examines age differences in emotional experience among a group of people with functional disabilities. In prior studies, health problems were predominantly concentrated among older adults in the sample (e.g., Piazza et al., 2007). This skewed age distribution accurately reflects the greater prevalence of health problems in later life, but asks a somewhat different question from the one in the current paper. Our goal was to examine how patterns of age differences in daily emotional experiences and responses to daily stressors may vary for groups of people who differ on disability status.

\section{Age, emotional well-being, and context}

The current investigation builds on a growing number of studies that have examined age differences in well-being among samples of people who are faced with highly distressing situations, and do not find age-related benefits. For example, SAVI posits that a loss of social belonging represents a life context in which older adults lose age-related advantages in affective well-being (e.g., Hawkley \& Cacioppo, 2007). In line with these predictions, one study showed that in response to a social evaluative stressor, lonely older adults exhibited higher levels of reactivity and dampened recovery compared to their non-lonely and younger counterparts (Ong, Rothstein, \& Uchino, 2012). Moreover, SAVI predicts that in the face of uncontrollable, chronic, or severe stressors, patterns of age differences in affective responses favoring older age may be attenuated or reversed. Consistent with this interpretation, an experience sampling study showed that when older individuals were confronted with complex hassles that influenced multiple life domains, they fared similar to, or even worse than, younger individuals in their affective responses to hassles (Wrzus, Müller, Wagner, Lindenberger, \& Riediger, 2013). In contrast, older age was associated with less affective reactivity to hassles when dealing with circumscribed hassles that only affected one life domain, which presumably requires fewer coping efforts and resources.

\section{Limitations and future directions}

Life context offers one explanation for our findings showing that people with spinal cord injury do not display age differences in affective experience. Normative aging is associated with changes in life contexts that benefit daily affective well-being (e.g., Brose, Scheibe, \& Schmiedek, 2013; Charles et al., 2010; Luong et al., 2011). For example, older adults are more likely to be retired, finished with child-rearing and, barring ill-health, have fewer 
constraints on how they spend their day than their younger counterparts who may have more competing demands on their time. Living with SCI, however, may nullify these age-related advantages, given that the condition is often accompanied by disruptions in daily routines, social networks, and resource capacities to cope with stressors (e.g., McColl \& Rosenthal, 1994). The current study, however, did not study more micro-level processes to identify differences in these daily demands.

The study also did not include potential mediating mechanisms (e.g., physiological reactivity; use of specific emotion regulation strategies) that may account for the observed differences in age-related patterns between the SCI and NSDE samples. For example, SAVI would predict that one reason why older participants with SCI report lower affective wellbeing than their older, non-injured counterparts is that they are less able to effectively disengage from a caustic situation. Without directly asking people if they actively disengaged from a stressor, however, we are unable to adequately test this possibility. Thus, future research would benefit from a thorough examination of the types of emotion regulation strategies people living in different life contexts employ when faced with adverse situations.

It is also important to note that the use of cross-sectional data prevents us from ruling out the possibility that pre-existing sample differences may account for the current findings. For example, it may be the case that even prior to their injury, the SCI sample already exhibited lower levels of affective well-being compared to the NSDE II sample. Developmental trajectories also cannot be tested without longitudinal studies. Future studies should include prospective longitudinal designs to account for possible individual differences in affective experiences prior to injury, and to examine group differences in trajectories of affective experience and plausible mediating mechanisms therein.

Moreover, despite the matching process, the two samples varied on many demographic variables. In response, we adjusted for relevant group difference variables in our analyses, and matched for the most pertinent variables. One thing we were unable to assess, however, was possible cognitive impairment, as this was not assessed in either sample. Although individuals with brain injuries were excluded from participating in the study, we cannot ignore the possibility that cognitive functioning may have played a role in our findings. Finally, whereas the NSDE II sample completed 8 daily diary assessments, the SCI sample completed 15 days of interviews in order to provide sufficient statistical power given the smaller sample size. Thus, selection biases could have contributed to these differences whereby younger and more highly educated individuals with SCI may have been more motivated to participate in the study. It is notable, however, that even if such selection biases were present in the current study, the SCI sample still failed to show the same age-related advantages in affective experiences as the NSDE II sample.

\section{Conclusion}

The current study compared two national daily diary datasets of participants spanning a wide age range and who differed according to life context - namely, significant disability - which is posited to influence age-related patterns of affective experience in daily life. Our study makes important advances in the literature by testing theoretical predictions from SAVI in 
novel ways to understand under which circumstances we may (or may not) expect to observe age-related advantages in daily affective experiences and responses to stressors. We found that in a situation where resources are taxed and older adults may be unable to leverage the emotion regulatory strengths of aging (i.e., in the context of severe functional disability), age-related advantages were attenuated or non-existent. The results bolster support for SAVI and provide a more comprehensive understanding of aging with a disability and its implications for affective well-being. Moreover, they reveal that perhaps the best way to assist older adults in difficult, chronically stressful situations is by providing environmental supports that would allow them to limit their exposure to aversive situations as opposed to focusing on cognitive strategies of emotion regulation.

\section{Acknowledgments}

This work was supported by National Institute of Aging and the National Institutes of Health by grants awarded to Susan Charles (R01AG042431) and to David M. Almeida (grant numbers P01AG020166, R01AG019239).

\section{References}

Aldwin CM, Jeong Y-J, Igarashi H, Choun S, Spiro A III. Do hassles mediate between life events and mortality in older men? Longitudinal findings from the VA Normative Aging Study. Experimental Gerontology. 2014; 59:74-80.10.1016/j.exger.2014.06.019 [PubMed: 24995936]

Aldwin CM, Sutton KJ, Chiara G, Spiro A III. Age differences in stress, coping, and appraisal: Findings from the Normative Aging Study. Journals of Gerontology: Psychological Sciences. 1996; 51B:179-183.

Almeida, DM.; Horn, MC. Is daily life more stressful during middle adulthood?. In: Brim, OG.; Ryff, CD.; Kessler, RC., editors. How healthy are we? A national study of well-being at midlife. Chicago: University of Chiacgo Press; 2004. p. 425-451.

Almeida DM, Wethington E, Kessler RC. The daily inventory of stressful events: An interview-based approach for measuring daily stressors. Assessment. 2002; 9:41-55.10.1177/1073191102091006 [PubMed: 11911234]

Alschuler KN, Jensen MP, Sullivan-Singh SJ, Borson S, Smith AE, Molton IR. The association of age, pain, and fatigue with physical functioning and depressive symptoms in persons with spinal cord injury. Journal of Spinal Cord Medicine. 2013; 36:483-491. [PubMed: 23941796]

Barry LC, Soulos PR, Murphy TE, Kasl SV, Gill TM. Association between indicators of disability burden and subsequent depression among older persons. The Journals of Gerontology Series A: Biological Sciences and Medical Sciences. 2013; 68(3):286-292.

Birditt KS, Fingerman KL. Do we get better at picking our battles? Age group differences in descriptions of behavioral reactions to interpersonal tensions. Journals of Gerontology: Psychological Sciences. 2005; 60:121-128.10.1093/geronb/60.3.P121

Birditt KS, Fingerman KL, Almeida DM. Age differences in exposure and reactions to interpersonal tensions: A daily diary study. Psychology and Aging. 2005; 20:330 340.10.1037/0882-7974.20.2.330 [PubMed: 16029096]

Blanchard-Fields F. Everyday problem solving and emotion: An adult developmental perspective. Current Directions in Psychological Science. 2007; 16:26-31.10.1111/j.1467-8721.2007.00469.x

Bombardier CH, Richards JS, Krause JS, Tulsky D, Tate DG. Symptoms of major depression in people with spinal cord injury: implications for screening. Archives of Physical Medicine and Rehabilitation. 2004; 85:1749-1756. [PubMed: 15520969]

Brose A, Scheibe S, Schmiedek F. Life contexts make a difference: Emotional stability in younger and older adults. Psychology and Aging. 2013; 28:148-159.10.1037/a0030047 [PubMed: 23066802]

Cacioppo, JT.; Berntson, GG.; Bechara, A.; Tranel, D.; Hawkley, LC. Could an aging brain contribute to subjective well-being? The value added by a social neuroscience perspective. In: Todorov, A.; 
Fiske, S.; Prentice, D., editors. Social neuroscience: Toward understanding the underpinnings of the social mind. New York: Oxford University Press; 2011. p. 249-262.

Carstensen LL. The influence of a sense of time on human development. Science. 2006; 312:19131915.10.1126/science.1127488 [PubMed: 16809530]

Carstensen LL, Bulent T, Scheibe S, Ram N, Ersner-Hershfield H, Samanez-Larkin GR, Nesselroade JR. Emotional experience improves with age: Evidence based on over 10 years of experience sampling. Psychology and Aging. 2011; 26:21-33.10.1037/a0021285 [PubMed: 20973600]

Charles ST. Strength and vulnerability integration: A model of emotional well-being across adulthood. Psychological Bulletin. 2010; 136:1068-1091.10.1037/a0021232 [PubMed: 21038939]

Charles ST, Carstensen LL. Social and emotional aging. Annual Review of Psychology. 2010; 61:383409.10.1146/annurev.psych.093008.100448

Charles ST, Luong G. Emotional experience across adulthood: The theoretical model of strength and vulnerability integration. Current Directions in Psychological Science. 2013; 22:443448.10.1177/0963721413497013

Charles ST, Luong G, Almeida DM, Ryff C, Sturm M, Love G. Fewer ups and downs: Daily stressors mediate age differences in negative affect. Journals of Gerontology: Psychological Sciences. 2010; 65B:279-286.10.1093/geronb/gbq002

Charles ST, Piazza JR. Age differences in affective well-being: Context matters. Social \& Personality Psychology Compass. 2009; 3:711-724.10.1111/j.1751-9004.2009.00202.x

Charles ST, Piazza JR, Luong G, Almeida DM. Now you see it, now you don't: Age differences in affective reactivity to social tensions. Psychology and Aging. 2009; 24:645-653.10.1037/ a0016673 [PubMed: 19739920]

Charles ST, Piazza JR, Mogle J, Sliwinski MJ, Almeida DM. The wear and tear of daily stressors on mental health. Psychological Science. 2013; 24:733-741.10.1177/0956797612462222 [PubMed: 23531486]

Degraff AH, Schaffer J. Emotion-focused coping: A primary defense against stress for people living with spinal cord injury. Journal of Rehabilitation. 2008; 74:19-24.

Diehl M, Hay EL. Risk and resilience factors in coping with daily stress in adulthood: The role of age, self-concept incoherence, and personal control. Developmental Psychology. 2010; 46:11321146.10.1037/a0019937 [PubMed: 20822228]

Dryden DM, Saunders LD, Rowe BH, May LA, Yiannakoulias N, Svenson LW, Voaklander DC. Depression following traumatic spinal cord injury. Neuroepidemiology. 2005; 24:5561.10.1159/000086284 [PubMed: 15947491]

Fuhrer MJ. The subjective well-being of people with spinal cord injury: Relationships to impairment, disability and handicap. Topics in Spinal Cord Injury Rehabilitation. 1996; 1:56-71.

Garshick E, Kelley A, Cohen SA, Garrison A, Tun CG, Gagnon D, Brown R. A prospective assessment of mortality in chronic spinal cord injury. Spinal Cord. 2005; 43:408-416.10.1038/ sj.sc.3101729 [PubMed: 15711609]

Gerstorf D, Ram N, Mayraz G, Hidajat M, Lindenberger U, Wagner GG, Schupp J. Late-life decline in well-being across adulthood in Germany, the United Kingdom, and the United States: Something is seriously wrong at the end of life. Psychology and Aging. 2010; 25:477-485.10.1037/a0017543 [PubMed: 20545432]

Giannini MJ, Bergmark B, Kreshover S, Elias E, Plummer C, O'Keefe E. Understanding suicide and disability through three major disabling conditions: Intellectual disability, spinal cord injury, and multiple sclerosis. Disability and Health Journal. 2010; 3:74-78.10.1016/j.dhjo.2009.09.001 [PubMed: 21122771]

Hawkley LC, Cacioppo JT. Aging and loneliness: Downhill quickly? Current Directions in Psychological Science. 2007; 16:187-191.10.1111/j.14678721.2007.00501.x

Hoffman JM, Bombardier CH, Graves DE, Kalpakjian CZ, Krause JS. A longitudinal study of depression from 1 to 5 years after spinal cord injury. Archives of Physical Medicine and Rehabilitation. 2011; 92:411-418. [PubMed: 21353823]

Hoffman L, Stawski RS. Persons as context: Evaluating between-person and within-person effects in longitudinal analysis. Research in Human Development. 2009; 6:97$120.10 .1080 / 15427600902911189$ 
Isaacowtiz DM, Blanchard-Fields F. Linking process and outcome in the study of emotion and aging. Perspectives on Psychological Science. 2012; 7:3-17.10.1177/1745691611424750 [PubMed: 22888369]

Kemp BJ, Krause JS. Depression and life satisfaction among people ageing with post-polio and spinal cord injury. Disability and Rehabilitation. 1999; 21:241-249. [PubMed: 10381236]

Kessler RC, Andrews G, Colpe LJ, Hiripi E, Mroczek DK, Normand SLT, Zaslavsky AM. Short screening scales to monitor population prevalences and trends in non-specific psychological distress. Psychological Medicine. 2002; 32:959-976. http://dx.doi.org/10.1017/ S0033291702006074. [PubMed: 12214795]

Krause JS. Changes in adjustment after spinal cord injury: A 20-year longitudinal study. Rehabilitation Psychology. 1998a; 43:41-55. http://dx.doi.org/10.1037/0090-5550.43.1.41.

Krause JS, Crewe NM. Chronologic age, time since injury, and time of measurement: Effect on adjustment after spinal cord injury. Archives of Physical Medicine and Rehabilitation. 1991; 72:91-100. [PubMed: 1991022]

Kunzmann U, Little TD, Smith J. Is age-related stability of subjective well-being a paradox? Crosssectional and longitudinal evidence from the Berlin Aging Study. Psychology and Aging. 2000; 15:511-526.10.1037/0882-7974.15.3.511 [PubMed: 11014714]

Labouvie-Vief G. Dynamic integration: Affect, cognition, and the self in adulthood. Current Directions in Psychological Science. 2003; 12:201-206.10.1046/j.0963-7214.2003.01262.x

Leary M. Responses to social exclusion: Social anxiety, jealousy, loneliness, depression, and low selfesteem. Journal of Social \& Clinical Psychology. 1990; 9:221-229.10.1521/jscp.1990.9.2.221

Lenze EJ, Rogers JC, Martire LM, Mulsant BH, Rollman BL, Dew MA, Reynolds CF III. The association of late-life depression and anxiety with physical disability: a review of the literature and prospectus for future research. American Journal of Geriatric Psychiatry. 2001; 9:113-135. [PubMed: 11316616]

Lucas RE. Adaptation and the set-point model of subjective well-being: Does happiness change after major life events? Current Directions in Psychological Science. 2007; 16:75-79.10.1111/j. 1467-8721.2007.00479.x

Luong G, Charles ST. Age differences in affective and cardiovascular responses to a negative social interaction: The role of goals, appraisals, and emotion regulation. Developmental Psychology. 2014; 50:1919-1930.10.1037/a0036621 [PubMed: 24773101]

Luong G, Charles ST, Fingerman KL. Better with age: Social relationships across adulthood. Journal of Social and Personal Relationships. 2011; 28:9-23.10.1177/0265407510391362 [PubMed: 22389547]

Lysack C, Komanecky M, Kabel A, Cross K, Neufeld S. Environmental factors and their role in community integration after spinal cord injury. Canadian Journal of Occupational Therapy. 2007; $74: 243-254$.

Marmot M, Ryff CD, Bumpass LL, Shipley M, Marks NF. Social inequalities in health: Next questions and converging evidence. Social Science and Medicine. 1997; 44:901-910. [PubMed: 9080570]

McColl MA, Rosenthal C. A model of resource needs of aging spinal cord injured men. Paraplegia. 1994; 32:261-270.10.1038/sc.1994.46 [PubMed: 8022636]

Migliorini C, Tonge B, Taleporos G. Spinal cord injury and mental health. Australian and New Zealand Journal of Psychiatry. 2008; 42:309-314.10.1080/00048670801886080 [PubMed: 18330773]

Mroczek DK. Age and emotion in adulthood. Current Directions in Psychological Science. 2001; 10:87-90.10.1111/1467-8721.00122

National Spinal Cord Injury Statistics Center. Facts and figures at a glance. 2013. Retrieved from NSCISC website: https://www.nscisc.uab.edu/PublicDocuments/fact_figures_docs/Facts $\% 202013$.pdf

Neugarten BL. Time, age, and the life cycle. American Journal of Psychiatry. 1979; 136:887-894. [PubMed: 453348]

Neupert SD, Almeida DM, Charles ST. Age differences in reactivity to daily stressors: The role of personal control. Journals of Gerontology: Psychological Sciences. 2007; 62:216-225. 
Noreau L, Fougeyrollas P. Long-term consequences of spinal cord injury on social participation: The occurrence of handicap situations. Disability and Rehabilitation. 2000; 22:170-180. [PubMed: 10798305]

Ong AD, Mroczek DK, Riffin C. The health significance of positive emotions in adulthood and later life. Social and Personality Compass. 2011; 1(5):538-551.10.1111/j.1751-9004.2011.00370.x

Ong AD, Rothstein JD, Uchino BN. Loneliness accentuates age differences in cardiovascular responses to social evaluative threat. Psychology and Aging. 2012; 27:190-198.10.1037/a0025570 [PubMed: 22004517]

Park DC. Aging, cognition, and culture: A neuroscientific perspective. Neuroscience \& Biobehavioral Reviews. 2002; 26:859-867.10.1016/S0149-7634(02)00072-6 [PubMed: 12470698]

Piazza JR, Charles ST, Almeida DM. Living with chronic health conditions: Age differences in affective well-being. Journals of Gerontology: Psychological Sciences. 2007; 62:313-321.

Post MWM, Van Dijk AJ, Van Asbeck FWA, Schrijvers AJP. Life satisfaction of persons with spinal cord injury compared to a population group. Scandinavian Journal of Rehabilitation Medicine. 1998; 30:23-30. [PubMed: 9526751]

Raudenbush, SW.; Bryk, AS. Hierarchical linear models: Applications and data analysis methods. Thousand Oaks, CA: Sage; 2002.

Riediger M, Schmiedek F, Wagner GG, Lindenberger U. Seeking pleasure and seeking pain: Differences in prohedonic and contra-hedonic motivation from adolescence to old age. Psychological Science. 2009; 20:1529-1535.10.1111/j.1467-9280.2009.02473.x [PubMed: 19891749]

Salthouse TA. What and when of cognitive aging. Current Directions in Psychological Science. 2004; 13:140-144.10.1111/j.0963-7214.2004.00293.x

Schopp LH, Clark MJ, Hagglund KJ, Sherman AK, Stout BJ, Gray DB, Boninger ML. Life activities among individuals with Spinal Cord Injury living in the community: Perceived choice and perceived barriers. Rehabilitation Psychology. 2007; 52:82-88.10.1037/0090-5550.52.1.82

Sliwinski MJ, Almeida DM, Smyth J, Stawski RS. Intraindividual change and variability in daily stress processes: Findings from two measurement-burst diary studies. Psychology and Aging. 2009; 24:828-840.10.1037/a0017925 [PubMed: 20025399]

Stone AA, Schwartz JE, Broderick JE, Deaton A. A snapshot of the age distribution of psychological well-being in the United States. Proceedings of the National Academy of Sciences. 2010; 107:9985-9990.10.1073/pnas.1003744107

Stroebe M, Schut H, Stroebe W. Health outcomes of bereavement. Lancet. 2007; 370:1960 1973.10.1016/S0140-6736(07)61816-9 [PubMed: 18068517]

Watson D, Clark LA, Tellegen A. Development and validation of brief measures of positive and negative affect: The PANAS scales. Journal of Personality and Social Psychology. 1988; 54:10631070. [PubMed: 3397865]

Wolff JL, Starfield B, Anderson G. Prevalence, expenditures, and complications of multiple chronic conditions in the elderly. Journal of the American Medical Association: Internal Medicine. 2002; 162:2269-2276.10.1001/archinte.162.20.2269

Wrzus C, Luong G, Wagner GG, Riediger M. Can't get it out of my head: Age differences in affective responses vary with elapsed time after, and preoccupation with, daily hassles. Emotion. 2015; 15:257-269.10.1037/emo0000019 [PubMed: 25286070]

Wrzus C, Müller V, Wagner GG, Lindenberger U, Riediger M. Affective and cardiovascular responding to unpleasant events form adolescence to old age: Complexity of events matters. Developmental Psychology. 2013; 49:384-397.10.1037/a0028325 [PubMed: 22545845]

Yeo JD, Walsh J, Rutkowski S, Soden R, Craven M, Middleton J. Mortality following spinal cord injury. Spinal Cord. 1998; 36:329-336. [PubMed: 9601112] 


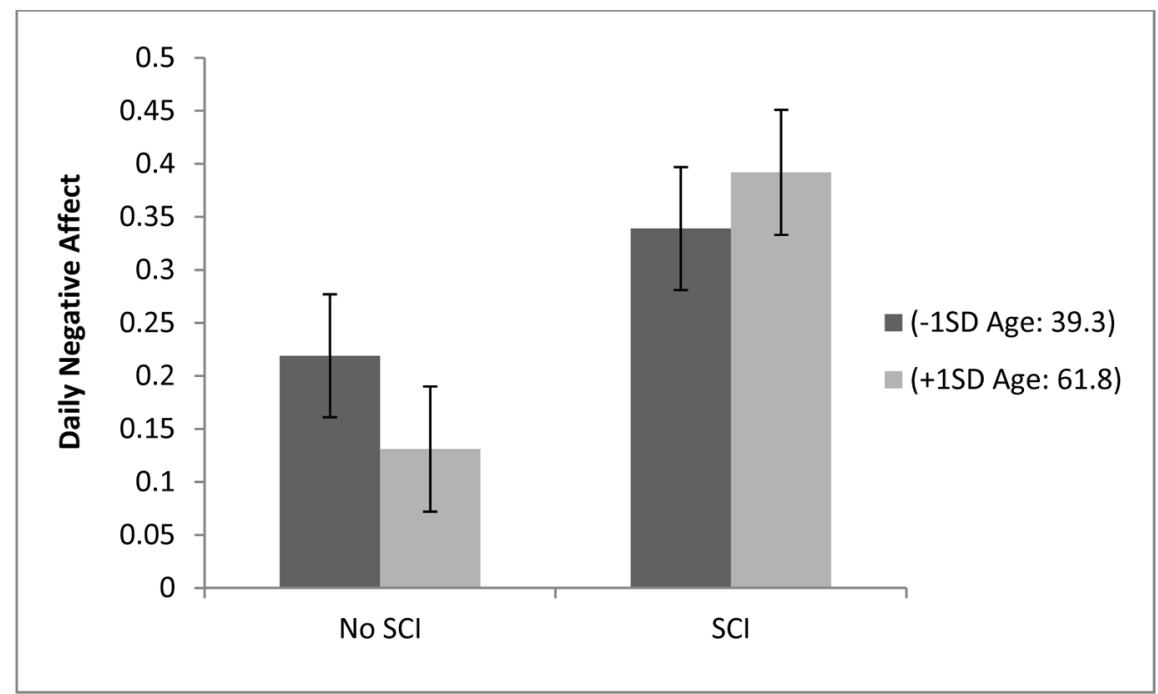

Figure 1.

Age and sample differences in daily negative affect. 


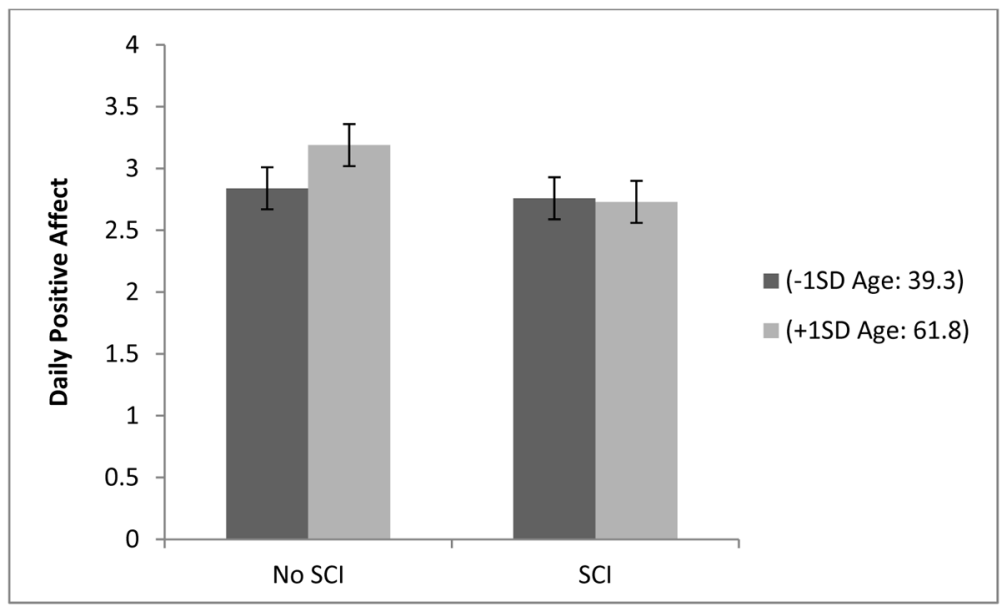

Figure 2.

Age and sample differences in daily positive affect. 


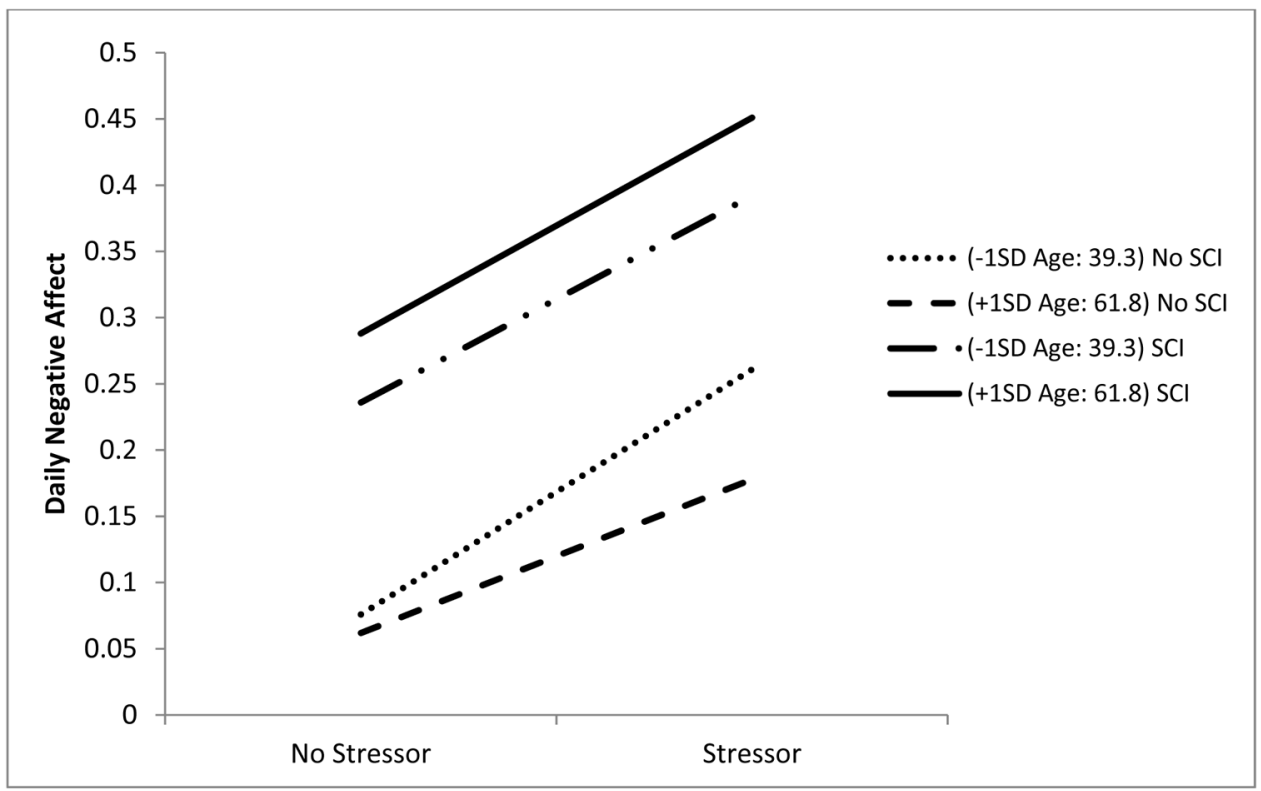

Figure 3.

Age and sample differences in negative affective reactivity to daily stressors. 


\section{Table 1}

Sample Characteristics of the NSDE II and SCI samples

\begin{tabular}{|c|c|c|}
\hline & NSDE II sample (\%) & SCI sample (\%) \\
\hline \multicolumn{3}{|l|}{ Gender } \\
\hline Female & 50.6 & 54.1 \\
\hline \multicolumn{3}{|l|}{ Education } \\
\hline$<$ High School & 1.9 & 2.8 \\
\hline High School Degree & 13.0 & 12.2 \\
\hline Some College & 34.8 & 37.8 \\
\hline Bachelor's Degree & 50.3 & 47.2 \\
\hline \multicolumn{3}{|l|}{ Ethnicity $^{* * *}$} \\
\hline White & 90.1 & 76.8 \\
\hline Black & 2.8 & 9.4 \\
\hline Asian & 0.8 & 2.2 \\
\hline Hispanic & 3.6 & 7.7 \\
\hline Other & 2.8 & 3.8 \\
\hline \multicolumn{3}{|l|}{ Marital Status $* * *$} \\
\hline Married & 75.4 & 48.3 \\
\hline Separated & 1.7 & 2.8 \\
\hline Divorced & 10.8 & 16.7 \\
\hline Widowed & 2.5 & 5.6 \\
\hline Never Married & 9.7 & 26.7 \\
\hline \multicolumn{3}{|l|}{${ }^{*}<.05$} \\
\hline \multicolumn{3}{|l|}{$*^{* *} \mathrm{p}<.01$} \\
\hline $\mathrm{p} * .001$ & & \\
\hline
\end{tabular}

Psychol Aging. Author manuscript; available in PMC 2016 December 01. 
Table 2

Percentage of NSDE and SCI Participants Reporting Chronic Health Conditions

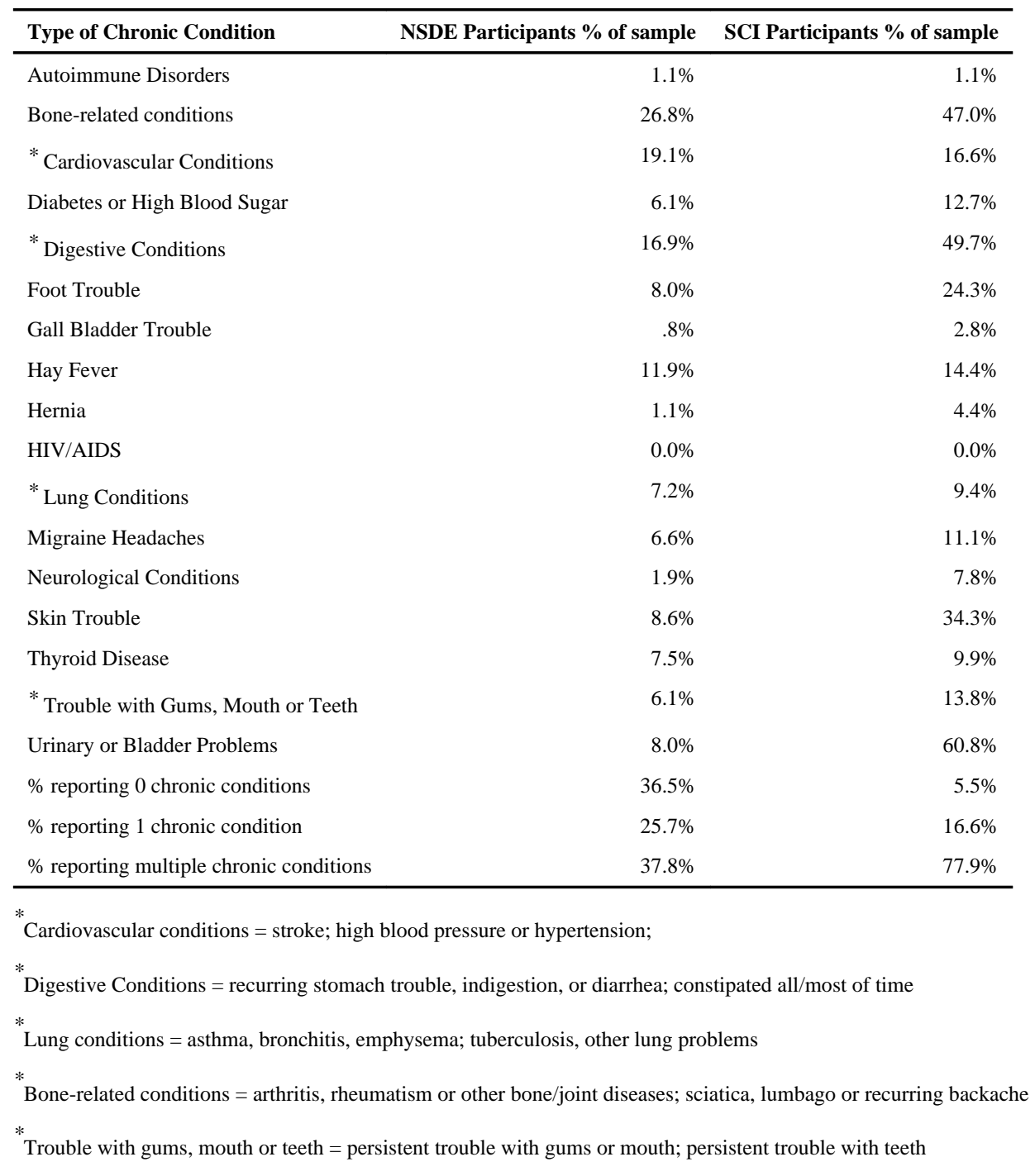


Table 3

Age and Sample Differences in Daily Negative Affect (NA) and NA Stressor Reactivity

\begin{tabular}{|c|c|c|}
\hline Fixed Effects & $\begin{array}{c}\text { Model 1 } \\
\text { Estimate (SE) }\end{array}$ & $\begin{array}{c}\text { Model 2 } \\
\text { Estimate (SE) }\end{array}$ \\
\hline Intercept & $.197(.047)^{* * *}$ & $.056(.037)$ \\
\hline Age & $-.004(.001)^{* * *}$ & $-.001(.001)$ \\
\hline Sex $($ ref $=$ female $)$ & $-.034(.020)$ & $.001(.016)$ \\
\hline Sample (ref = NSDE) & $.191(.038)^{* * *}$ & $.193(.029)^{* * *}$ \\
\hline \multicolumn{3}{|l|}{ Ethnicity (ref = White) } \\
\hline African American & $.006(.058)$ & $-.000(.046)$ \\
\hline Asian & $-.024(.048)$ & $.027(.037)$ \\
\hline Hispanic & $.052(.091)$ & $.056(.070)$ \\
\hline Other & $-.069(.046)$ & $-.060(.036)$ \\
\hline Education & $.011(.013)$ & $-.005(.010)$ \\
\hline \multicolumn{3}{|c|}{ Marital Status (ref = Married) } \\
\hline Separated & $-.056(.071)$ & $-.014(.055)$ \\
\hline Divorced & $-.008(.031)$ & $-.019(.024)$ \\
\hline Widowed & $.010(.057)$ & $.017(.044)$ \\
\hline Never Married & $.060(.030)^{*}$ & $.055(.024)^{*}$ \\
\hline Day & $-.007(.001)^{* * *}$ & $-.003(.001)^{* * *}$ \\
\hline Time since Injury & $-.003(.002)$ & $-.004(.001)^{* * *}$ \\
\hline Age x Sample & $.006(.002)^{* *}$ & $.003(.001)^{*}$ \\
\hline Stressor & & $.151(.012)^{* * *}$ \\
\hline Average \# Stressors & & $1.19(.139)^{* * *}$ \\
\hline Age x Stressor & & $-.003(.001)^{* *}$ \\
\hline Stressors x Sample & & $.009(.019)$ \\
\hline Stressors x Sample x Age & & $.003(.002)^{*}$ \\
\hline \multicolumn{3}{|l|}{$\underline{\text { Random Effects }}$} \\
\hline Intercept & $.046(.003)^{* * *}$ & $.022(.002)^{* * *}$ \\
\hline Stressor & & $.015(.003)^{* * *}$ \\
\hline Covariance & & $.010(.002)^{* * *}$ \\
\hline Residual & $.057(.001)^{* * *}$ & $.049(.001)^{* * *}$ \\
\hline \multicolumn{3}{|l|}{$\underline{\text { Model Fit }}$} \\
\hline AIC & 1053.8 & 335.2 \\
\hline $\mathrm{BIC}$ & 1131.1 & 442.5 \\
\hline \multicolumn{3}{|l|}{$\mathrm{p}<.05$} \\
\hline \multicolumn{3}{|l|}{${ }^{* *} \mathrm{p}<.01$} \\
\hline *** $\mathrm{p}<.001$ & & \\
\hline
\end{tabular}


Table 4

Age and Sample Differences in Daily Positive Affect (PA) and PA Stressor Reactivity

\begin{tabular}{|c|c|c|}
\hline Fixed Effects & $\begin{array}{c}\text { Model 1 } \\
\text { Estimate (SE) }\end{array}$ & $\begin{array}{c}\text { Model 2 } \\
\text { Estimate (SE) }\end{array}$ \\
\hline Intercept & $2.995(.143)^{* * *}$ & $3.130(.140)^{* * *}$ \\
\hline Age & $.016(.003)^{* * *}$ & $.012(.004)^{* * *}$ \\
\hline Sex $($ ref $=$ female $)$ & $-.008(.062)$ & $-.040(.061)$ \\
\hline Sample $($ ref $=$ NSDE $)$ & $-.274(.117)^{*}$ & $-.277(.114)^{*}$ \\
\hline \multicolumn{3}{|l|}{ Ethnicity (ref = White) } \\
\hline African American & $-.119(.176)$ & $-.074(.171)$ \\
\hline Asian & $-.003(.146)$ & $-.035(.142)$ \\
\hline Hispanic & $.099(.275)$ & $.080(.267)$ \\
\hline Other & $.351(.141)^{*}$ & $.347(.137)^{*}$ \\
\hline Education & $-.104(.040)^{*}$ & $-.067(.039)$ \\
\hline \multicolumn{3}{|c|}{ Marital Status (ref = Married) } \\
\hline Separated & $-.192(.218)$ & $-.196(.212)$ \\
\hline Divorced & $.147(.095)$ & $.142(.093)$ \\
\hline Widowed & $-.029(.175)$ & $-.046(.170)$ \\
\hline Never Married & $-.128(.093)$ & $-.142(.090)$ \\
\hline Day & $-.003(.002)$ & $-.006(.002)^{* *}$ \\
\hline Time since Injury & $.005(.005)$ & $.005(.005)$ \\
\hline Age x Sample & $-.017(.005)^{* *}$ & $-.014(.006)^{*}$ \\
\hline Stressor & & $-.182(.022)^{* * *}$ \\
\hline Average \# Stressors & & $-1.830(.464)^{* * *}$ \\
\hline Age $\mathrm{x}$ Stressor & & $.001(.002)$ \\
\hline Stressors x Sample & & $.044(.033)$ \\
\hline Stressors x Sample x Age & & $-.002(.003)$ \\
\hline \multicolumn{3}{|l|}{$\underline{\text { Random Effects }}$} \\
\hline Intercept & $.470(.030)^{* * *}$ & $.455(.030)^{* * *}$ \\
\hline Stressor & & $.025(.008)^{* * *}$ \\
\hline Covariance & & $-.022(.012)$ \\
\hline Residual & $.198(.004)^{* * *}$ & $.188(.004)^{* * *}$ \\
\hline \multicolumn{3}{|l|}{$\underline{\text { Model Fit }}$} \\
\hline AIC & 8007.9 & 7847.4 \\
\hline BIC & 8085.2 & 7954.7 \\
\hline \multicolumn{3}{|l|}{$\mathrm{p}<.05$} \\
\hline${ }^{* * *} p<.001$ & & \\
\hline
\end{tabular}

